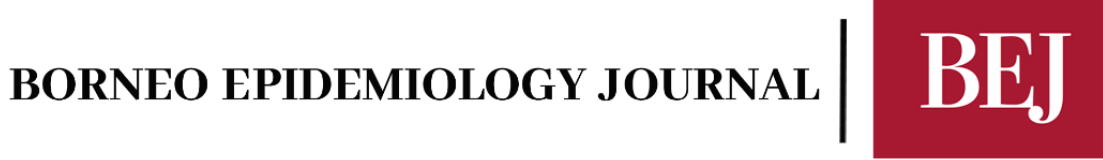

\section{Validity and Reliability of Knowledge, Attitude and Practice (KAP) Scale for Dog Bite Prevention in Children}

\author{
Syahrizal Abdul Halim ${ }^{1 *}$, Rosalia Saimon ${ }^{1}$, Parveen Kaur Sarjeet Singh ${ }^{2}$ and Razitasham \\ Safii ${ }^{1}$
}

\section{Abstract}

Introduction: Rabies is a highly fatal disease that is mostly caused by a dog bite. The Dog Bite Prevention KAP scale is a 30-item scale that is designed to measure children's level of safety knowledge on dog's behaviour, precautionary behaviour around dogs, perceived vulnerability towards dogs and help-seeking behaviour following a dog bite. Therefore, this study aimed to determine the test-retest reliability and validity of outcome measures.

Methods: This questionnaire was administered to samples of school student aged from 13 years to 14 years at a secondary school located in Bau District, Sarawak. They were purposively selected for a baseline interview (Time 1) and a ten-day follow-up (Time 2). This study was conducted within four months, which were from 10 April to 31 August 2018. Descriptive analysis, content analysis, Cronbach's alpha, intra-class correlation and exploratory factor analysis were performed in this study.

Results: A total of 64 boys and 114 girls were involved in the study, whereby $79.2 \%, 10.1 \%$, $7.9 \%, 2.2 \%$ and $0.6 \%$ of them were of Bidayuh ethnic, Chinese, Iban, Malays and other ethnic, respectively. The Cronbach's alpha was 0.796 . The test-retest intra-class correlation was adequate, with 0.84 for perceived vulnerability towards dogs and 0.81 for precautionary behaviour around dogs. Principal components analysis with varimax rotation resulted in two factors, which explained $39 \%$ of the variance (perceived vulnerability towards dogs) and $49 \%$ of the variance (precautionary behaviour around dogs).

Conclusion: The questionnaire is a valid and reliable tool for a dog-bite prevention survey.

Keywords: Knowledge, Precautionary, Vulnerability, Help-seeking

Correspondence Email: syahrizalabdulhalim@yahoo.com

${ }^{1}$ Faculty of Medicine and Health Sciences, Universiti Malaysia Sarawak, 94300 Kota Samarahan, Sarawak, Malaysia

${ }^{2}$ Faculty of Social Sciences and Humanities, Universiti Malaysia Sarawak, 94300 Kota Samarahan, Sarawak, Malaysia 